\title{
The Rise of Green Advertising
}

\author{
Rucha Dande* \\ Faculty of Climate Change and Sustainable Development. CEPT, India
}

\begin{abstract}
The last decade (2000) has witnessed an influx of green brands in the market due to consumer demand thus, permitting green marketing to emerge into a multidimensional strategic tactical process. Since consumers will always have environmental concerns there will be parallel rise in environmental advertising accompanying increased consumer interest in the environment. The purpose of the study was to establish that there is a difference over a time period in advertisements representation of the environment and then to identify how this difference in representation has been constructed. The study was conducted based on the 7 step methodology. It ranged from selection of medium, year and magazine, data collection and analysis, preparation of timeline and conclusion. To study the change in the contents of green ads 1 National Geographic magazine (print medium) was selected from 1960 to 2010 and 324 green ads were collected over 60 years. These ads were categorized in the sectors of automobiles, oil/cement, organizations and technologies. The second categorization of ads was based on the quality of ads i.e. strong, casual and emotional ads. To understand the changing trends and messages of green ads an institutional, political, communications and environmental timeline was made from 1960-2010. The timeline helped trace major events which have brought about environmental awareness amongst masses and also have triggered the rise in green advertising in the particular year due to the occurrence of the particular environmental event.

The findings suggested that the major investment in green advertising came from the automobile sector and also the advertisements are changing from strong to casual at a rapid pace. A comparative analysis of ads from before and today led to conclude that the messages and contents in green ads have been gradually changing from genuine environmental concern to the sole objective of 'product sale.'
\end{abstract}

Keywords: Climate change; Green advertising; Consumers; Environment events; Timeline

\section{Introduction}

Advertising has three functions, to inform, remind and persuade, the aim of green advertising is to create awareness and tentative strong attitudes towards brands and companies. The emergence of green challenge has brought about changes in consumers buying behaviour making it highly debatable topic from the point of view of academics. The last decade had witnessed an influx of green brands in the market due to consumer demand thus, permitting green marketing to emerge into a multidimensional strategic tactical process $[1,2]$.

Since consumers will always have environmental concerns [3] there will be parallel rise in environmental advertising accompanying increased consumer interest in the environment [1]. Consumers form feelings (affect) and judgments (cognition) when exposed to an advertisement which affects their attitude towards the ads and beliefs about the brand [4].

Climate change and the sustainable development have seen a great history since global warming was witnessed. Authors and media have played a central role in advertising the events and issues at the same time helping mainstream environmental issues. Greening of products and green branding are the major influences of climate change awareness in advertising market. Advertising is always a product of its time, and we live in interesting times. It is evident that we will be the first generation in the history of modern advertising to have to integrate climate change into our marketing and advertising strategies.

\section{Need for the Study}

Today the world is no more an easier place to live in. The world has ' $n$ ' number of problems to tackle ranging from combating climate changes to saving the meagre natural resources to meet the requirements of the ever increasing population. However, today awareness regarding the environment has increased amongst the masses and people are ready to shell out more on green products. Overall, consumers are less likely to cite hurdles to buying green. A majority of consumers in India, China and Brazil say they intend to spend more on green products. Consumers are putting a higher value on green products with $48 \%$ of Indian consumers and 55\% of Chinese consumers, willing to spend over $10 \%$ more on a product simply because it is green [3]. In developed countries, price is named as the greatest barrier to purchasing green. Most consumers here believe that green products and brands are more expensive than their non-green counterparts, and more than a third are unwilling to pay higher prices for green products. In the US and UK, only $22 \%$ and $13 \%$ of those surveyed were ready to spend more than $10 \%$ on green products, respectively [3]. The changing behaviours and choices of the consumers have greatly influenced the market to come out with more products that are green or to say 'environment friendly' to attract the consumer.

As consumers become more sophisticated on buying green, demand for green big-ticket products will tend to grow. Companies will have to adapt their marketing strategies to show not only the environmental impact and related "greenness "of their products, but also the larger end benefits in order to meet their customers' changing needs [3].

*Corresponding author: Rucha Dande, Faculty of Climate Change and Sustainable Development. CEPT, Ahmedabad, India, E-mail: ar.rucha.dande@gmail.com

Received October 09, 2012; Accepted November 28, 2012; Published December 07, 2012

Citation: Dande R (2012) The Rise of Green Advertising. J Mass Commun Journalism 2:133. doi:10.4172/2165-7912.1000133

Copyright: (c) 2012 Dande R. This is an open-access article distributed under the terms of the Creative Commons Attribution License, which permits unrestricted use, distribution, and reproduction in any medium, provided the original author and source are credited. 
What triggered the green bloom in advertising sector and which were the major events that brought greenness as a major subject for advertising. These questions can be answered only when the evolution of green advertising and its implications in today's context are thoroughly understood.

Aim: The aim of the study was to identify the change in the contents and messages of green ads from environmental perspective from 19602010 and give recommendations.

\section{The specific objectives of the study are outlined as follows}

- To study the evolution of green advertising on the basis of environment, world politics, institutions and communication timeline.

- To develop methodologies to undertake such kind of study.

- To analyze the change in advertising on the basis of various sectors.

\section{Scope and limitations}

The scope of the study was to analyze the ads in the print medium from 1960 to 2010. Advertisements are best conveyed through the TV medium, Radio, Internet however, due to time constraints only print medium was studied. The study was limited only to the National Geographic magazine and did not involve newspapers for the analysis.

\section{Methodology}

To conduct the study seven steps were followed:

$$
\begin{aligned}
& \text { 1. Selection of medium } \\
& \text { 2. Selection of year } \\
& \text { 3. Selection of magazine } \\
& \text { 4. Data collection } \\
& \text { 5. Data analysis } \\
& \text { 6. Timeline } \\
& \text { 7. Finding and Conclusions }
\end{aligned}
$$

\section{The first step involved selection of medium}

Advertisements are seen today in various mediums such as TV, Internet, and Newspaper which can be broadly categorized as print and TV medium. However, the TV medium is supposed to be the most effective of all other mediums since they are more promising and vocal. But print medium was selected because ads could be easily traced back from 1960.The study required availability of large data sets for analysis.

Print medium, by its structure, can convey concrete information more easily and thoroughly than broadcast media. Finally, studies have shown that of all advertising media, television is the most mistrusted [5] thus, the print medium was selected.

\section{Second step was the selection of the year from when the data was collected till 2010}

The advertising industry became more scientific in the 1960s. This period witnessed some of the most creative ads of all times. Instead of focusing on the product, ads endeavoured to strengthen the brand and create an image for the company. Advertising also became subtler and more intelligent, often adopting a conversational style. [6]

"Concern for the environment has awakened in the 1960's and has been steadily rising ever since." [7]
As a result 1960 was selected as the beginning year for the collection of data.

\section{The third step was selection of magazine for data collection}

The process involved reviewing different categories of magazine that had considerable number of ads in each issue from various fields and not pertaining to a particular subject. This was to avoid the bias during the analysis of ads. Magazines which were referred for selection were Down to Earth, National Geographic Architect and Design Builder, A+D. However these magazines had ads only related to the environment, building materials and interiors respectively and thus were eliminated from selection and National Geographic magazine was finalized for data collection since it had a holistic approach towards reporting.

\section{Fourth step was the data collection from 60 issues of National Geographic}

This stage involved daily review of a volume of National Geographic from 1960-2010 which lasted for about 45 days. All ads from each magazine from every volume were scrutinized for green ads and a photographic documentation was done for all the green ads. These ads were segregated year wise and data was prepared for analysis. The data was analyzed based on semiotics theories. This helped analyze each ad on the basis on semiotics principles and definitions. It involved the subject analysis of each ad on the basis of images, colors, language and statements used.

3 main areas which form semiotics are:

- The signs themselves

$$
\begin{aligned}
& \text { 1. Icon } \\
& \text { 2. Index } \\
& \text { 3. Symbol }
\end{aligned}
$$

- The way they are organized into systems

- The context in which they appear

The final result was collection of 324 green ads from various sectors over 60 issues of National Geographic which were further analyzed on the theories of semiotics.

\section{The fifth step was analysis of all the ads}

The green ads were analyzed through categorizing the ads sector wise.

Categorization of green ads was done in two steps.

Firstly advertisements were segregated on the basis of the companies those were involved in green advertising. These companies were as follows:

1. Automobiles

2. Oil/Cement

3. Organizations

\section{Technology}

After the collection of data each ad was further divided according to the pages covered ranging from 0.5 pages to 4 page advertisements. Subsequent it points were assigned depending on to the number of pages covered by the green ad, ranging from 1-8. These points were then tabulated for each year from 1960. 
Allotment of points was done to understand, the companies that engaged most of the pages and hence were ready to invest in green ads in order to promote their product through environmental concern. The result also helped understand the dominant sector in green advertising.

The second categorization was on the basis on the quality of ads. The ads were categorized as to how the ads conveyed their message and the way ads were constructed from environmental perspective. All the selected ads were analyzed on the basis of their way of bringing about the environmental message.

The ads were categorized as:

1. Strong2

2. Casual3

3. Emotional4

\section{The sixth step was making of a timeline}

The primary reason to make a timeline was to relate events in the environmental, political, institutional and communication sector. Timelines are particularly useful for studying history, as they convey a sense of change over time. Big events create an impacts on authors, scientist and media persons to incorporate latest events in their masterpieces as a result it becomes important to trace events from history.

In order to relate the rise of green advertising it was important to make a timeline of environmental events. For example timeline helped relate environmental awareness created after the book by Rachel Carlson in 1960's.Similarly many events in history could have influenced the rise of green advertising during the particular year and following years. The last step was to relate all the finding to the major events extracted from the timeline

\section{Findings}

All the 324 green advertisements from the national geographic magazine from the year 1960 to 2010 were analyzed on theories of signs and symbols. They were later categorized under sub headings to understand their quality and genuineness towards the environment. These ads were compared to the environmental timeline made from the year 1960 and were plotted on the graph.

The timeline consisted of major environmental events plotted under the category of environmental, institutional, political and communications categorized decade wise.

Such events were plotted with the graph of number of green ads from 1960-2010.

Such overlapping gave a clear graphical representation of the rise and fall of green ads over 60 years with the major corresponding world environmental events.

\section{Comparative analysis of the two categories}

Type of company and quality of ads showed that the numbers of green ads were increasing in the oil and petroleum sector. It was also observed that the numbers of casual ads are increasing considerably. The relation is evident that the evolution of green advertising has seen a drastic change from the number of ads to the companies that have started investing in green advertising. Green advertising has also seen the change in quality of ads from strong to casual. It can be concluded that the most polluting companies are the most casually advertised companies. Events such as the publishing of books 'limits to growth' and 'small is beautiful' in 1972 and 1973 respectively, Green belt movement, explosion of St. Helena, Bhopal gas tragedy in 1984, Montreal protocol in 1987,etc. and many such consecutive events has triggered environmental awareness amongst the masses and common man in those particular years.

As a result the environmental concerns got reflected in the advertising market as well. This gave rise to the increase in number of green ads from 1970.The number of ads grew from 1970 with minor fluctuations.1980 was the decade from when green ads grew tremendously and have still been rising. The total number of green ads in National Geographic magazine in 1970-80 decade was 30 and 41 green ads in the 1980-1990. 1990 saw steep rise in green ads followed by 148 ads in 2000 .

\section{The green ads were analyzed on the six parameters for their} quality and ability to convey the environmental message

After the primary segregation of ads into categories of strong, casual and emotional the ads were also analyzed for the mentioned parameters.

\section{Ad concern, message, target, size, the companies and design [8]}

It was found that the old ads (before 1980) had environmental concern but today its only product sale. Earlier the ads had a strong environmental message to convey to the public whereas today the ads are ambiguous and are only green in colour. The old ads were made so that the common man is also targeted through the ads; on the contrary today's ads only target the higher classes. Organizations and NGO's were the dominant companies which invested in green advertising whereas today the picture has changed and the dominant sector in green

Advertising are the giant oil companies. A clear picture that comes out from the analysis is that ads are becoming more and more casual in conveying messages. The primary objective of ads is turning into only product sale through ambiguous messages. As a result genuine advertising and genuine message conveyance is losing grip in environmental advertising sector. Also an interesting thing that comes out on comparison of the ads today and before is that the ads earlier were bland and lengthy but today the ads are very flashy, colorful which easily influences the reader.

\section{The study conducted by Penn Schoen}

Berland's has come out with interesting solution to the problems of green marketing. These issues were highlighted by the consumers. As a result they should be taken care of as the consumer is ultimately the end user for green products. The poll revealed that the consumers insisted that the companies should undertake activities like recycling product packaging, use of green labels that are easier to understand and also disclosure of the materials the products were using, etc. Only if these parameters are taken care of the companies can claim their product to be green and clean. From an Indian perspective, labels that tell where the food comes as well as the environmental impacts of the products are the most important area of concern. Whereas overall in all countries the general finding is that the consumers want companies to recycle their product packaging in order to make a green, company or product.

\section{Lately everything is advertised as green}

Be it a salon, food, vehicle, house, city as the matter of fact anything and everything can be advertised as green. Earlier, the concept of green 
advertising was not common. The message conveyed by the green ad was towards the betterment of the environment and mankind. It was targeted to all types of consumers; ads were not specific for anyone in particular.

However the picture of green ads is changing that is turning more flashy and ambiguous. Such advertisements mislead the consumer to a great extent. Companies have started making consumers shell out heavy amount from pockets in the name of green. People have started becoming aware of the state of environment today. They are ready to pay heavy amounts in order to save their environment but are cheated and misled. Big companies are greening their products to get attention and public response, they are taking complete advantage of the fact that people are willing to pay for green products. But at this stage what the consumer wants is clear labelling of green products, language that is more legible, packaging recycling by the company itself and choice of products to choose from.

Such issues and solutions if taken care of as far as green advertising is concerned the environment will surely benefit but the consumers will be satisfied too.

Green is not just a colour or the latest trend but green needs to be within all of us. It is the way of our mind and soul. We need not buy green products to be environment friendly but need to act greener. Emergence of green products and green brands is a good start for the betterment of the environment but it is not the only solution. Lastly I would like to quote that green is not the new IN but it is WITHIN all of us, we just need to find it and act accordingly.

A small movie through famous cartoon characters Tom and Jerry was made to highlight how people fall prey to the green strategies of companies for product sale. The message that was conveyed through the movie was that one should have a green gene to act green and contribute towards the betterment of the environment and thereby making it greener.

\section{References}

1. Peattie K (1999) Green marketing (M\&E handbook series). Macdonald \& Evans, London.

2. Carlson L, Grove SJ, Kangun N (1993) A content analysis of environmenta advertising claims: a matrix method approach. Journal of Advertising 22: 27-39.

3. Berland PS, Landor, cohn, wolfe (2011) Green brands india insights, Esty environmental partners.

4. Batra R, Ray ML (1986) Affective responses mediating acceptance of advertising. Journal of consumer research 13: 234-249.

5. Shrum LJ, John A, Mccarty, Lowrey TM (1995) Buyer characteristics of the green consumer and their implications for advertising strategy. Journal of advertising 24: 71-82.

6. http://pdf.employmentcrossing.com/advertising/170123.pdf

7. Zinkhan GM, Carlson $L$ (1995) Green advertising and the reluctant consumer. Journal of Advertising 24: 1-6.

8. Banerjee S, Gulas SC, Iyer E (1995) Shades of green : A multi dimensiona analysis of environmental advertising. journal of advertising 24: 21-31. 